\title{
A review of the community flood risk management literature in the USA: lessons for improving community resilience to floods
}

\author{
Jenna Tyler ${ }^{1} \cdot$ Abdul-Akeem Sadiq $^{1} \cdot$ Douglas S. Noonan ${ }^{2}$
}

Received: 10 October 2018 / Accepted: 23 March 2019

(c) Springer Nature B.V. 2019

\begin{abstract}
This study systematically reviews the diverse body of research on community flood risk management in the USA to identify knowledge gaps and develop innovative and practical lessons to aid flood management decision-makers in their efforts to reduce flood losses. The authors discovered and reviewed 60 studies that met the selection criteria (e.g., study is written in English, is empirical, focuses on flood risk management at the community level in the USA, etc.). Upon reviewing the major findings from each study, the authors identified seven practical lessons that, if implemented, could not only help flood management decision-makers better understand communities' flood risks, but could also reduce the impacts of flood disasters and improve communities' resilience to future flood disasters. These seven lessons include: (1) recognizing that acquiring open space and conserving wetlands are some of the most effective approaches to reducing flood losses; (2) recognizing that, depending on a community's flood risks, different development patterns are more effective at reducing flood losses; (3) considering the costs and benefits of participating in FEMA's Community Rating System program; (4) engaging community members in the flood planning and recovery processes; (5) considering socially vulnerable populations in flood risk management programs; (6) relying on a variety of floodplain management tools to delineate flood risk; and (7) ensuring that flood mitigation plans are fully implemented and continually revised.
\end{abstract}

Keywords Flood risk $\cdot$ Community flood risk management $\cdot$ Community resilience

Jenna Tyler

jentyler@knights.ucf.edu

Abdul-Akeem Sadiq

abdul-akeem.Sadiq@ucf.edu

Douglas S. Noonan

noonand@iupui.edu

1 School of Public Administration, University of Central Florida, Orlando, USA

2 School of Public and Environmental Affairs, Indiana University-Purdue University Indianapolis, Indianapolis, USA

This is the author's manuscript of the article published in final edited form as:

Tyler, J., Sadiq, A.-A., \& Noonan, D. S. (2019). A review of the community flood risk management literature in the USA: Lessons for improving community resilience to floods. Natural Hazards, 96(3), 1223-1248. 


\section{Introduction}

Floods have and continue to pose significant threats to communities in the USA (Cigler 2017; Consoer and Milman 2017; Sadiq 2017; Sadiq and Noonan 2015a, b). In fact, of all the natural hazards, floods are the costliest and result in the most lives lost and property damage (Cigler 2017; Kick et al. 2011). Recent disasters, including the 2016 Louisiana floods as well as Hurricanes Harvey, Irma, and Maria, illustrate the devastating impacts floods can have on local communities in the USA (National Weather Service 2017). The devastation caused by these disasters and others stems from the interaction of the physical, social, built, and political environments (Brody et al. 2011). Indeed, persistent development along the US coastlines and floodplains coupled with increased precipitation and rising sea levels has exacerbated communities' flood risks (Bouwer 2011; Brody et al. 2010). Furthermore, scholars argue that federal flood policies and programs in the USA are costly, ineffective, and have inadvertently encouraged development in high-risk flood zones (Cigler 2017; Strother 2016). The US National Flood Insurance Program (NFIP), for example, subsidizes the costs associated with living and doing business in high-risk flood zones at the expense of taxpayers (Strother 2016).

Amid the Intergovernmental Panel on Climate Change's (IPCC) (2013) prediction of increases in the frequency and severity of flood disasters engendered by climate change, there is a potential for increased flood impacts. In light of these predictions, scholars have argued that a focus on community flood risk management is an effective way to reduce flood damages in the USA (Pielke and Downton 2000). In this study, the term "community" takes on a geographic connotation and refers to a single or collection of states, counties, and/or neighborhoods. Furthermore, community flood risk management is defined as actions taken by government and non-government actors, with a purpose to better understand and/or reduce flood risks at the state, county, and/or neighborhood levels (Mees et al. 2016). Examples of community flood risk management activities include, but are not limited to, adopting structural (e.g., constructing dams, levees, seawalls, etc.) and non-structural (e.g., regulating land use, revitalizing wetlands, etc.) mitigation measures, drafting and implementing comprehensive flood mitigation plans, and providing community members with information on flood risks (Brody et al. 2010). Mitigation, in this study, refers to actions taken to reduce flood losses. The authors chose to exclusively focus on community flood risk management in the USA to ensure that the practical lessons identified are relevant and applicable to flood management decision-makers in the USA. For example, while there is an abundance of studies on community flood risk management around the world, the policies, practices, and approaches that are relevant and effective in other countries may not be as relevant and effective in the USA. Indeed, differences in governance structures and processes, topography, weather patterns, and social vulnerabilities will have implications for developing effective community flood risk management strategies (Jongman et al. 2018).

Addressing flood risks at the community level is important because flood risks involve interdependent physical, political, social, and ecological interactions (Brody et al. 2011). In addition, the community level is amenable to implementing comprehensive flood risk management initiatives. This partly explains why the number of studies on flood risk management conducted at the community level in the USA has steadily increased over the past decade. Given the importance of understanding flood risk management at the community level and the myriad studies done on this topic, there is a compelling need to synthesize this large body of research as a means to identify practical lessons to improve communities' 
resilience to future flood disasters. Resilience, in this study, refers to a community's ability to absorb the effects of a flood disaster and adapt to reduce the effects of future flood disasters (Cutter et al. 2008). Moreover, scholars (e.g., Morrison et al. 2017) have called for increased transfer of important findings on flood risk management from the academic community to practitioners and policymakers. The present study addresses these needs by systematically reviewing the diverse body of research on community flood risk management in the USA. In doing so, it identifies knowledge gaps as well as innovative and practical lessons that, if implemented, could not only help flood management decision-makers better understand communities' flood risks, but could also reduce the impacts of flood disasters and improve communities' resilience to future flood disasters.

We organize the remainder of the paper as follows. The next section discusses flood risk governance in the USA. The third section describes the methodology, including the search strategy and the selection criteria. The fourth section presents the results and major findings, and the fifth section identifies practical lessons for flood management decisionmakers to improve their communities' resilience to future flood disasters. The sixth section describes different knowledge gaps and identifies directions for future research. The paper concludes by discussing the implications of our findings for flood risk management scholars and practitioners and highlighting a few study limitations.

\section{Flood risk governance in the USA}

Initial attempts to manage flood risks in the USA date back to the early 1900s, with the federal government assuming principal responsibility (Galloway 2008). For example, in 1936, Congress passed the Flood Control Act, which provided the United States Army Corps of Engineers (USACE) and other federal agencies with the authority to design, develop, and maintain hundreds of civil engineering projects (e.g., dams, levees, and dikes) to reduce flood losses (Haddow et al. 2011). Through the 1960s, the federal government maintained this structural approach to flood management (Galloway 2008). In fact, it was not until the passage of the National Flood Insurance Act of 1968 that the federal government took a serious interest in engaging in more non-structural flood mitigation measures. A major component of this act was the establishment of the NFIP. The purpose of the NFIP was and continues to be to reduce flood risks by requiring participating communities to adhere to a set of floodplain management standards and to offer flood insurance to properties with a significant flood risk (Horn and Brown 2018). Following the passage of the National Flood Insurance Act, states began to assume a major role in floodplain management as they were required to adhere to NFIP standards and began advising and supporting their participating NFIP localities (Mittler et al. 2006).

To incentivize communities to implement floodplain management activities that go beyond those required under the NFIP, the Federal Emergency Management Agency (FEMA) created the Community Rating System (CRS) program. The CRS is a federal, voluntary program whereby communities that participate in the CRS are eligible to receive reductions in their flood insurance premiums. If a community decides to participate in the program, they accumulate credit points as they adopt additional flood mitigation activities. Examples of creditable activities include, but are not limited to, establishing higher regulatory standards, engaging in outreach projects, and constructing dams and levees (see the CRS Coordinator Manual for a full list of the 19 creditable activities: https://www.fema. gov/media-library/assets/documents/8768). As communities accrue credit points, they 
improve their CRS class. CRS classes range from 10 to 1 . A class 10 community represents a community that does not participate in the CRS or that has not accrued enough credit points to receive any discounts in flood insurance premiums. Conversely, a class 1 community represents a community that has accrued the maximum amount of credit points, thus receiving a $45 \%$ discount in flood insurance premiums (so long as the community is located in a Special Flood Hazard Area [SFHA], an area with a one percent chance of flooding in any given year). Intermediate classes receive discounts in flood insurance premiums in increments of $5 \%$.

Today, flood risk management is primarily a function of local governments (e.g., cities and counties), especially local emergency and floodplain managers. Whereas emergency managers are responsible for coordinating efforts to mitigate, prepare, respond, and recover from any and all disasters and emergencies, floodplain managers are responsible for developing, implementing, and overseeing the community's floodplain management program. This frequently includes "enforcing the community's flood damage prevention ordinance, updating flood maps, plans, and policies of the community, and any of the activities related to administration of the National Flood Insurance Program" (Association of State Floodplain Managers 2010, p. 1). Depending on the size and structure of a locality, the emergency and floodplain manager may be a dual job title and, thus, occupied by the same local government employee. However, in other communities, the floodplain manager is a second job title of a city or county community development director, engineer, building code official, or zoning officer (Tyler 2018; Tyler and Sadiq 2018). Rarely, is a floodplain manager the sole function of a local government employee. Rather than using the terms floodplain manager or emergency manager to describe the individuals that play a decision-making role in managing communities' flood risks, the authors use the term "flood management decision-makers" to include policymakers and other agencies and groups that are involved in making decisions to minimize a community's flood risks.

\section{Methods}

\subsection{Selection criteria}

The selection criteria used to identify studies for inclusion are: (1) written in English; (2) focus on flood risk management at the community level; (3) examine the USA; (4) peerreviewed journal article, conference paper, conference proceeding, or dissertation; (5) are empirical by relying on experience or observations (studies might use primary and/or secondary data as well as quantitative and/or qualitative data). One of the authors reviewed the title and abstract of all the papers generated by each keyword search to determine whether the paper met the criteria for inclusion. If a paper met the criteria for inclusion, the researcher obtained a full-text version of the article. However, if the paper did not meet the criteria, this author listed it in the category of exclusions and noted the reason for exclusion (e.g., not written in English, did not focus on the USA, etc.). If this researcher could not determine whether the article met the selection criteria by looking at the title and abstract, a full-text version of the article was obtained for further inquiry in order to make the final eligibility determination. 


\subsection{Search strategy}

We adopted a three-stage approach to identify relevant studies. Stage one involved searching papers indexed in three academic databases-Google Scholar, Science Direct, and Web of Science (Bubeck et al. 2012; Morrison et al. 2017; Thompson et al. 2017). The search of these academic databases began in May of 2017 using the keyword "Community Rating System" and "FEMA." We began the search with this keyword because studies examining community flood risk management in the USA typically reference FEMA's CRS program. This keyword search yielded 890 results from Google Scholar, 29 from Science Direct, and six from Web of Science. We identified additional studies by searching the three literary databases using the following keywords "community flood risk management," "community flood policy," "community flood risk," and "community flood management." These searches generated an additional 202 unique studies. Although we completed the keyword searches on June 16, 2017, we used Google Scholar Alerts to receive additional studies that contained any of the keywords until December 31, 2017. These alerts yielded 45 more studies. In total, we screened and reviewed 1,172 papers and 1,053 papers, respectively. After the review process, 44 studies matched the selection criteria (see Fig. 1).

In stage two, we e-mailed a list containing the initial 44 studies to six experts on community flood risk management to validate our list and to add any missing eligible studies. By expert, we mean individuals that have published extensively on community flood risk management and whose works are well cited. These experts are from different disciplines such as city and regional planning, sociology, urban and regional sciences, and economics.

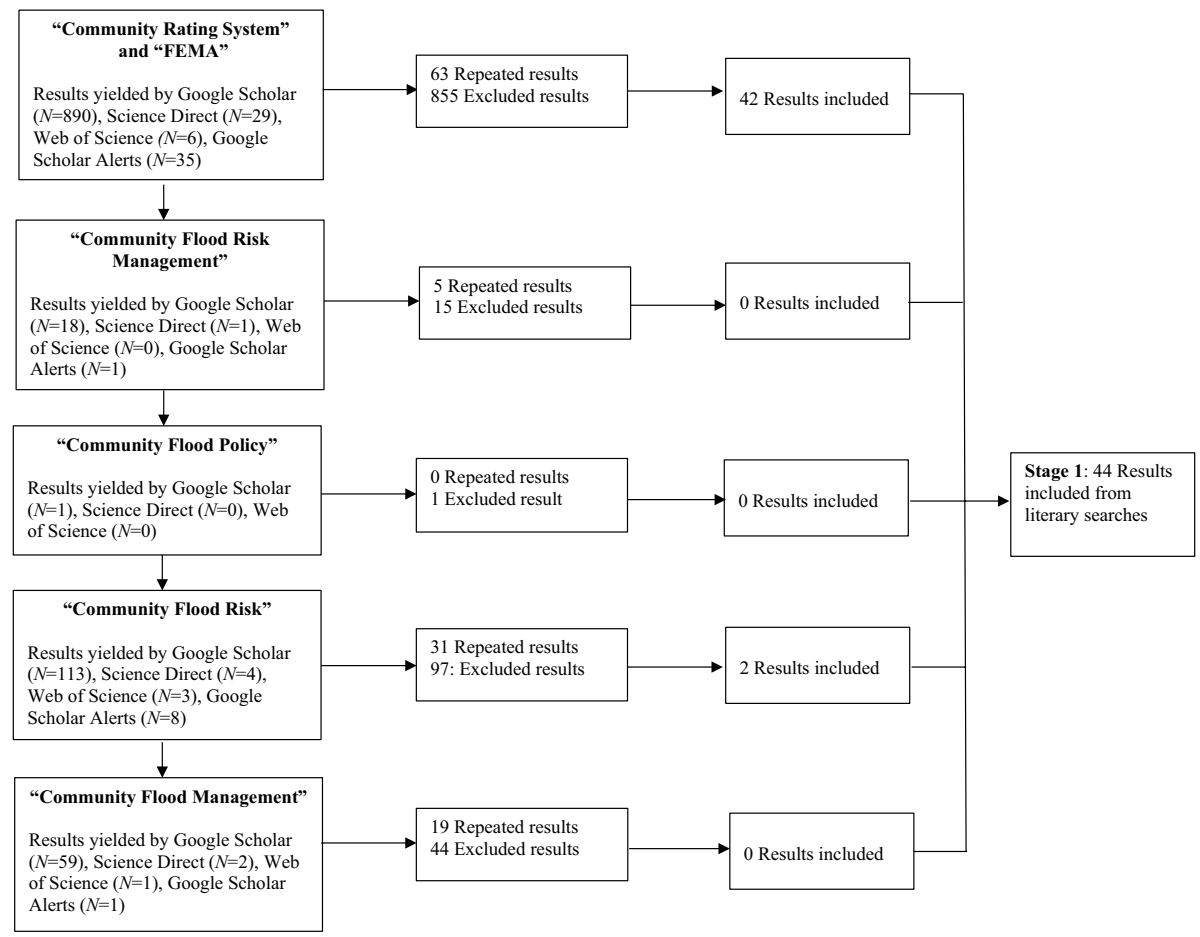

Fig. 1 Diagram of studies selected for inclusion from stage 1 
Furthermore, these experts are at varying stages of their academic careers, with one expert holding the rank of an assistant professor, two holding the rank of associate professor, two holding the rank of full professor, and one serving as the managing director for a university research center. All six of the experts validated the 44 studies, and some of them recommended ten additional studies. After reviewing their ten recommended studies, only two met our selection criteria. This brings the total number of studies to 46 at the end of stage two.

In stage three, we carried out a backward citation search (Thompson et al. 2017) by going through the references of all 46 studies. Through this process, we discovered 14 new studies that met the selection criteria. At the end of the third and final stage, we had a total of 60 studies that met our selection criteria and are included in the review. Figure 2 presents a graphical illustration of the three-stage approach used for selecting the 60 studies.

\subsection{Coding strategy}

Two of the authors reviewed and coded the 60 studies included in the review. Specifically, these authors identified the methodological qualities of each study such as the research question, study area, sample size, dependent and independent variables, data sources,

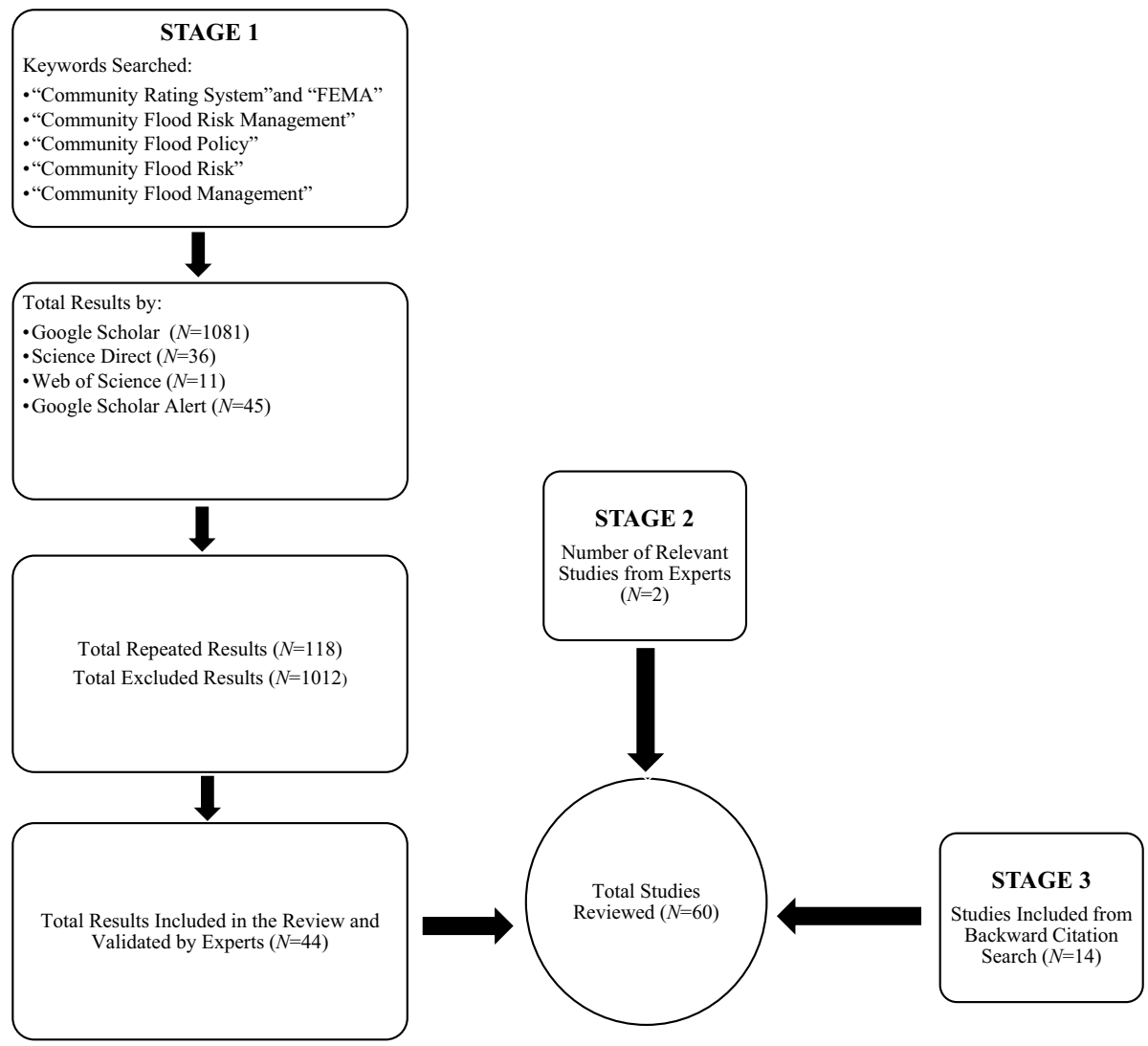

Fig. 2 Three-stage approach for study selection 
analytical approach, and major findings. To ensure inter-coder reliability, these two authors separately reviewed and coded ten randomly selected articles from the 60 studies eligible for review. After reviewing and coding the ten articles, these two individuals compared their codes and discovered only one discrepancy in codes. The authors resolved this discrepancy by consensus. The remaining 50 studies were evenly distributed to the two authors and were coded individually. No additional issues were found.

\section{Results}

\subsection{Methodological qualities of included studies}

Two of the authors coded various methodological qualities of the 60 studies included in this review. First, the authors organized the research question(s) and/or the purpose of each study into six themes: mitigating community flood losses $(N=20)$; FEMA's CRS program $(N=16)$; perceptions and responses to flood events and flood policies $(N=9)$; understanding communities' flood risks $(N=7)$; flood mitigation tools $(N=6)$; and communities' efforts to plan for flood events $(N=2)$. Next, the authors identified the number of studies that focus on a coastal area $(N=20)$, inland area $(N=6)$, or both $(N=32)$. Then, the authors identified the study location for each study, which was measured as the specific state(s) where each study was conducted. The majority of studies were conducted, at least in part, in Texas $(N=17)$ or Florida $(N=15)$ (see Fig. 3$)$. The authors also coded whether the study employed quantitative or qualitative methodologies as well as whether the study relied on primary or secondary data. The authors found that the majority of studies included in the review are quantitative $(N=54)$ and rely on secondary data $(N=47)$ gathered from government sources. Finally, the authors recorded study sample sizes and found the maximum and minimum sample sizes reported are 1.8 million and 1 , respectively.

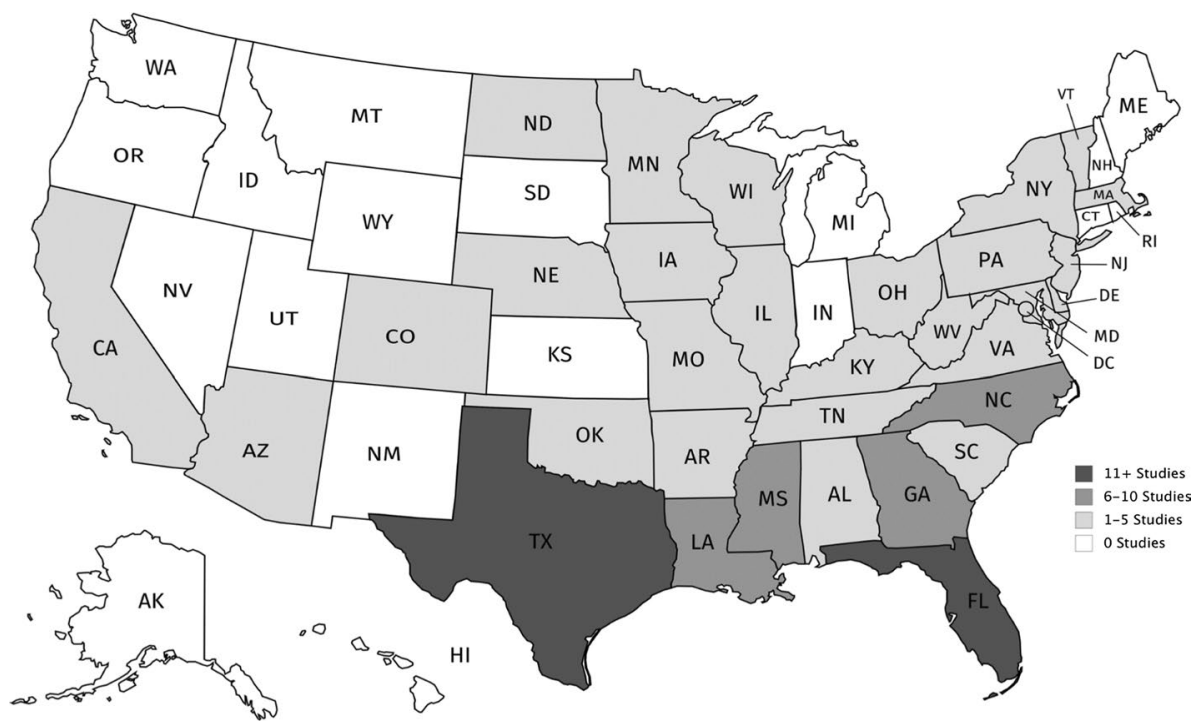

Fig. 3 Map showing the distribution of studies by state 
In addition to assessing the methodological qualities of the 60 studies, the authors ascertained whether there has been a general upward trend in the number of published community flood risk management studies as well as where the majority of the community flood risk management studies have been published. According to Fig. 4, the number of publications on community flood risk management has increased since 2006; the highest number of publications $(N=8)$ was in 2014 and 2015. The rise in the number of studies since 2006 makes sense because it was not until then that the term or the practice of "flood risk management" became more widely recognized (Galloway 2008). Finally, in terms of publication outlet, the journal with the highest number of publications is Natural Hazards Review $(N=8)$, followed by dissertations $(N=6)$. Twenty one of the 32 publication outlets published one study each.

\subsection{Major findings from the community flood risk management literature}

The authors recorded the major findings for all 60 studies. The authors organize the findings based on the following six research themes that were identified when analyzing each study's research question(s) and/or purpose: mitigating community flood losses $(N=20)$; FEMA's CRS program $(N=16)$; perceptions and responses to flood events and flood policies $(N=9)$; understanding communities' vulnerabilities and flood risks $(N=7)$; flood mitigation tools $(N=6)$; and communities' efforts to plan for flood events $(N=2)$.

Studies examining how communities can mitigate flood losses indicate that acquiring and conserving open space (Brody and Highfield 2013; Brody et al. 2014, 2017; Calil et al. 2015), protecting naturally occurring wetlands (Brody et al. 2007a, b, c, 2015b; Highfield and Brody 2006), and specific development patterns can significantly reduce flood losses (Brody et al. 2011, 2013). Acquiring and conserving open space is an effective strategy for reducing flood risks as it focuses on locating high-risk, flood-prone areas, preventing highdensity development in these areas, and using these areas as a means to store flood waters (Brody et al. 2007a, 2017).

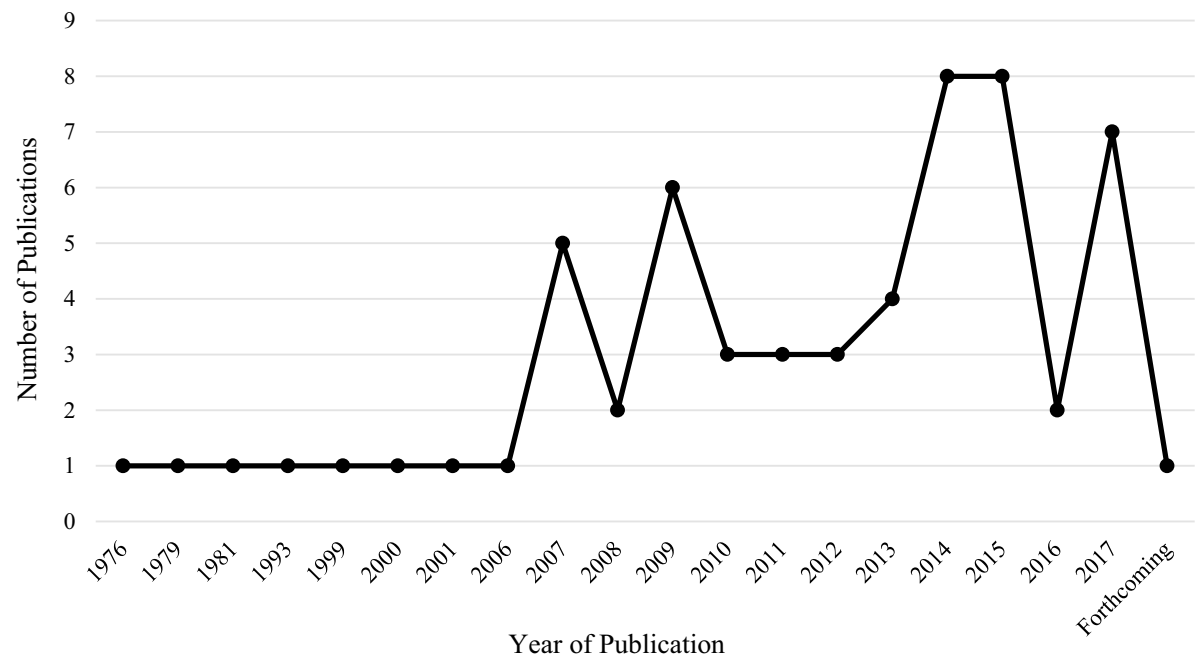

Fig. 4 Number of community flood risk management publications by year $(N=60)$ 
Wetlands are an effective flood mitigation tool because they help facilitate a properly functioning water cycle (Brody et al. 2007b) and are able to absorb and hold large amounts of flood water (Brody et al. 2007c). Furthermore, local land configuration and development patterns have important implications for community flood risk management as they not only influence where flood water goes, but also determine whether development will occur in flood-prone areas (Brody et al. 2017).

Studies included under FEMA's CRS program indicate that local capacity, flood risk, socioeconomic characteristics, and political economy factors are significant predictors of initial and continuing participation in the CRS program (Asche 2013; Landry and Li 2011, 2018; Li 2012; Paille et al. 2016; Sadiq and Noonan 2015a, b). This body of research also demonstrates that participation in FEMA's CRS program is indeed an effective strategy for reducing communities' flood losses (Highfield and Brody 2013, 2017).

The studies included under the theme, perceptions, and responses to flood events and policies show the importance of stakeholder engagement in flood recovery processes (Albright and Crow 2015a, b) and how state and federal policies impact mitigation (Berke et al. 2014; Deegan 2007; Kick et al. 2011; Paul and Milman 2017). Moreover, the studies that examined existing flood mitigation tools indicate that the 100-year floodplain may not be a sufficient tool for measuring community flood risks (Blessing et al. 2017; Brody et al. 2012a; Patterson and Doyle 2009).

The studies included under understanding communities' vulnerabilities and flood risks suggest that societal (e.g., sociodemographic characteristics), physical (e.g., landscape features), and institutional (e.g., organizational capacity) factors contribute to a community's flood risk (Brody et al. 2009b, 2010; Chakraborty et al. 2014; Consoer and Milman 2017; Mogollón et al. 2016; Zahran et al. 2008). More specifically, these studies indicate that communities with higher percentages of socially vulnerable populations (Zahran et al. 2008) and lower organizational capacity (Brody et al. 2009b, 2010) have greater flood risks and that larger floods cannot be managed by solely manipulating landscape structure (Mogollón et al. 2016). Finally, and somewhat surprisingly, studies examining communities' efforts to plan for flood events demonstrate that the development and quality of mitigation plans has little effect on flood losses (Bailey 2017; Kang 2009). Table 1 in "Appendix" presents summaries of each study's major findings.

\section{Discussion}

The authors identified a set of practical lessons that emanated from the themes and major findings presented in Table 1 in "Appendix." While these lessons are developed to be relevant to flood management decision-makers throughout the USA, we recognize that these lessons may not be suitable for every community. Hence, we argue that, when applicable, flood management decision-makers should consider implementing these lessons. The level of applicability will largely depend on a community's flood risks and resources such as funding, staff, and experience. We organize these lessons based on the previous themes identified: mitigating community flood losses; FEMA's Community Rating System program; perceptions and responses to flood events and flood policies; understanding communities' vulnerabilities and flood risks; flood mitigation tools; and communities' efforts to plan for flood events. 


\subsection{Mitigating community flood losses}

Lesson 1: Recognize that acquiring open space and conserving wetlands are some of the most effective approaches to reducing flood losses.

One of the most consistent findings among the community flood risk management scholarship is that acquiring open space significantly reduces the amount of damage caused by flood events (Brody and Highfield 2013; Brody et al. 2017; Calil et al. 2015). Acquiring open space refers to a three-step process, whereby emphasis is placed on locating high-risk, flood-prone areas, preventing high-density development in these areas, and using these areas as a means to store flood waters (Brody et al. 2007a, 2017). Furthermore, because open spaces typically contain less impervious surfaces compared to commercial or residential areas, they can be used to accommodate recreational facilities or parks (Brody et al. 2015b, 2017). In the USA, the decision to acquire land to use for open space is embedded in local land use and planning documents (Brody and Highfield 2013). Furthermore, the acquisition of open space can be established through a number of techniques, including "zoning provisions, fee simple purchase, conservation easements, setbacks, the transfer of development rights, and conservation overlay zones" (Brody et al. 2017, p. 226). Participating in FEMA's buyout program is an additional method for acquiring open space. This program uses federal funds from FEMA's Hazard Mitigation Grant Program to fund up to $75 \%$ of the cost for buying out repetitive loss properties (FEMA 2014a). Conserving wetlands represents another flood mitigation tool that significantly reduces flood damages (Brody et al. 2007a, b, c, 2015b, 2017; Highfield and Brody 2006). In fact, Brody et al. (2007b) contend that the alteration of naturally occurring wetlands is the most important built-environment indicator of flood damage. The practical lesson to be learned from these studies is that flood management decision-makers should consider pursuing an avoidance strategy whereby emphasis is placed on acquiring open spaces and conserving wetlands to mitigate flood risks, when applicable.

Lesson 2: Recognize that, depending on a community's flood risks, different development patterns are more effective at reducing flood losses.

Although flood losses have historically been explained as a function of geophysical characteristics (e.g., precipitation, soil, and topography), scholars have recently concluded that socioeconomic and built characteristics are also important predictors for explaining differences in flood loss (Brody et al. 2011). In light of this understanding, scholars (e.g., Brody et al. 2011, 2013, 2015a; Esnard et al. 2001; Kousky and Walls 2014) have sought to determine what specific development patterns are most effective at stemming flood losses based on a community's flood risk. Brody et al. (2011, 2013), for example, examine the influence of development patterns on flood losses along the Gulf Coast and find that as long as development is positioned away from flood-prone areas, clustered, highintensity development patterns (i.e., areas of development with more than $80 \%$ of development being impervious surfaces) significantly reduce the amount of reported property damage. The reason for this is that such high-intensity development patterns are typically designed to direct flood impact away from critical facilities, or equipped with flood mitigation measures such as retention ponds that can handle large amounts of runoffs, or use less land overall, thereby limiting flood impacts (Brody et al. 2013). Conversely, low-intensity 
development patterns exacerbate flood property damages because they may lack adequate storm drainage systems, thus placing more people in harm's way (Brody et al. 2011, 2013). The practical lesson to be learned from these studies is that flood management decisionmakers should cluster development in areas with low flood risk and build high-quality stormwater infrastructure such as retention ponds that would help reduce the impacts of flooding.

\subsection{FEMA's Community Rating System program}

Lesson 3: Consider the costs and benefits of participating in FEMA's CRS program.

Recall FEMA's CRS program is a federal voluntary program that was created in 1990 to incentivize communities to implement floodplain management activities that go beyond those required under the NFIP. By adopting additional flood mitigation measures, communities receive reductions in their flood insurance premiums. The number of studies on the CRS program has burgeoned over the past decade (the authors are currently aware of 44 studies that assess the CRS in some regard (see Sadiq et al. 2018)), presumably because of the perceived benefits of participation (e.g., reduced flood risks and lower flood insurance premiums) and the minimal number of communities that participate in the program (FEMA 2017; Highfield and Brody 2017; Sadiq and Noonan 2015a, b). The extant research indicates that CRS participating communities experience substantially less flood losses compared to communities that do not participate in the program (Highfield and Brody 2017). In fact, Highfield and Brody (2017) found that CRS participating communities experience a $41.6 \%$ overall average reduction in flood claims compared to communities with similar characteristics that do not participate in the program. Moreover, Highfield and Brody (2013) find that the following three CRS activities result in the greatest reduction in flood damages: freeboard requirements (i.e., elevating structures above the base flood elevation), open space protection (i.e., limiting development in flood-prone areas and using these areas to store flood waters), and flood protection (e.g., retrofitting buildings and constructing small flood control projects). One practical lesson from these studies is that local flood management decision-makers should consider the costs and benefits of participating in the CRS program if they have not done so already. Furthermore, communities already participating in the CRS should focus on implementing the following three CRS activities, as these activities have been shown to result in the greatest reduction in flood damages: freeboard requirements, protecting open space, and engaging in flood protection activities like retrofitting structures or improving storm sewage systems (Highfield and Brody 2013).

\subsection{Perceptions and responses to flood events and flood policies}

Lesson 4: Engage community members in the flood planning and recovery processes.

When flood disasters occur, they provide an opportunity for communities to learn from their experiences and to adjust their policies moving forward (Albright and Crow 2015a). How these policies are developed, however, depends on the individuals and groups that are involved in the discussions and decision-making processes (Albright and Crow 2015a, b). Indeed, Albright and Crow's (2015a) analysis of public participatory processes in the aftermath of the 2013 Colorado floods shows that who participates in flood recovery processes 
influences how flood risks are perceived at the community level. Findings also suggest that communities with more open and deliberative public participatory processes lead to greater change and learning (Albright and Crow 2015a). In a related study, Albright and Crow (2015b) explore the depth of stakeholder participation in the aftermath of the 2013 Colorado floods. The authors find, among other results, that communities that have suffered damages across many sectors and have limited financial capacity are more likely to have motivated residents and interested organizations participate in flood recovery and planning processes. Another study also indicates that the relationship between community members and local flood management decision-makers has important implications on a community's recovery trajectory (Kick et al. 2011). For example, Kick et al. (2011) find that flood victims engage in less mitigation when there is a lack of trust between local flood management officials and flood victims and when flood victims perceive local flood management official to be unhelpful during the recovery to a flood event. The practical lesson here is that community engagement is imperative when planning and recovering from flood disasters as such engagement can improve communities' understanding of their flood risks and build trust between community members and local flood management decision-makers.

\subsection{Understanding communities' vulnerabilities and flood risks}

Lesson 5: Consider socially vulnerable populations in flood risk management programs.

Socially vulnerable populations are typically characterized as having a combination of higher poverty rates, lower median household incomes, and higher percentages of nonHispanic white residents (Zahran et al. 2008), among other factors. Furthermore, studies indicate that communities containing more socially vulnerable populations are not only less prepared for flood disasters, but also face higher flood risks (Chakraborty et al. 2014; Zahran et al. 2008). Chakraborty et al. (2014), for example, assess the extent to which flood risks differ by social groups across flood zones in Miami, Florida. The authors find that socially disadvantaged populations are significantly overrepresented in inland zones and underrepresented in coastal flood zones. Studies also indicate that socially vulnerable populations suffer disproportionately in terms of flood injuries and deaths (Zahran et al. 2008). Zahran et al. (2008), for example, find that the odds of a flood casualty significantly increase with higher percentages of socially vulnerable populations. These findings, however, are not particularly surprising given that other studies have found that socially vulnerable populations lack the financial capacity to prepare and respond to disasters, have limited access to social and political resources, and are less likely to receive disaster information and obey evacuation warnings (Zahran et al. 2008).

The practical lesson to be learned from these studies is that socially vulnerable populations face unique challenges when it comes to flood risk management. As a result, flood management decision-makers should invest in flood management activities specifically for socially vulnerable populations before, during, and after flood events. For example, communities can purchase wheelchair-accessible vans that could be used to evacuate individuals with access and functional needs during flood events. In addition, flood management decision-makers should engage in bidirectional communication processes whereby socially vulnerable populations and flood management decision-makers work together to better understand flood risks (Kellens et al. 2013). Furthermore, flood mitigation plans, policies, and procedures should account for the obstacles socially vulnerable populations experience during flood events (e.g., lack of transportation and language barriers) and identify ways to minimize these challenges 
(Eisenman et al. 2007). Finally, according to Chakraborty et al. (2014), flood management decision-makers should continue to advocate for socially vulnerable populations and ensure that flood insurance rates remain subsidized for economically disadvantaged communities with high flood risks under the Biggert-Waters Act of 2012. Although the 2014 Homeowner Flood Insurance Affordability Act addressed this issue to some extent as it repealed certain rate increases and stopped policy increases for some subsidized policyholders (FEMA 2014b), floodplain management decision-makers should remain cognizant of the financial constraints socially vulnerable populations face when purchasing flood insurance.

\subsection{Flood mitigation tools}

Lesson 6: Rely on a variety of floodplain management tools to delineate flood risk.

The 100-year floodplain has historically been used as the primary tool for determining a community's flood risks. Communities that are located in a 100-year floodplain have a one percent chance of flooding in any given year (FEMA 2017). However, studies indicate that the 100-year floodplain may not be a sufficient marker for delineating communities' flood risks (Brody et al. 2012a, b; Patterson and Doyle 2009). Indeed, Brody et al. (2012a) found that the 100-year floodplain may not be the best indicator for predicting property damage caused by flood events affecting coastal watersheds. Moreover, Patterson and Doyle's (2009) analysis of five counties in North Carolina indicates that there was a significant increase in flood exposure immediately outside the 100-year floodplain. A possible explanation for these findings is that FEMA flood maps that establish whether there is a 100year floodplain in a given community are not regularly updated. In fact, some communities are still relying on the flood maps that were first created in the 1970s and 1980s (Gallagher 2014). An additional explanation for these findings is that NFIP building standards only apply to those inside the regulatory floodplain.

In light of these studies' findings, we suggest that in addition to the 100-year floodplain, flood management decision-makers should consider using a variety of methods like rasterbased inundation modeling (see Horritt and Bates 2001) and spatially distributed hydrological models (see Blessing et al. 2017) to delineate flood risks.

\subsection{Communities' efforts to plan for flood events}

Lesson 7: Ensure that flood mitigation plans are fully implemented and continually revised.

To apply and receive funding under FEMA's hazard mitigation assistance grant programs, local communities must develop comprehensive multi-hazard mitigation plans (FEMA 2015). These plans identify the hazards that threaten the local community, assess community needs, and outline a strategy for reducing the risks associated with the hazards identified (FEMA 2015). Somewhat surprisingly, studies examining community-level planning for flood events indicate that the development and quality of mitigation plans have little effect on flood losses (Bailey 2017; Kang 2009). For example, Bailey's (2017) analysis of the Mississippi River region shows that counties with mitigation plans experienced higher flood costs in comparison with counties without plans. Moreover, Kang's (2009) study of 
mitigation plans in Florida indicates that plan quality had little effect on reducing insured flood damage, even after controlling for biophysical, built environment, and socioeconomic variables. There are a few explanations for these findings. The most plausible explanation relates to implementation (Kang 2009). That is, while communities develop multi-hazard mitigation plans, they may not follow through with implementing the strategies set forth in the plan. The inability to implement these strategies is likely a function of a lack of community resources and/or a lack of coordination and commitment by local flood management decision-makers. Another explanation for these findings is that while communities with higher flood risks and more frequent disasters tend to develop better mitigation plans and implement additional hazard mitigation policies, NFIP flood policies often lead to increased development in flood risk areas, which in turn limits the effectiveness of mitigation plans. This explanation relates to the "safe-development paradox" and refers to the idea that NFIP construction standards can stimulate development in flood-prone areas by providing a false sense of security that increases individuals' willingness to reside in flood-prone areas (Burby 2006). The practical lesson here is that those in charge of managing flood risks should consider the extent to which they have implemented their local multi-hazard mitigation plans as well as the potential for flood policies to promote development in flood risk areas.

\section{Knowledge gaps and future research directions}

Although the 60 studies included in this review provide a wealth of information on the current state of community flood risk management, knowledge gaps do exist. To identify knowledge gaps, the authors reviewed the limitations from each study as well as the directions for future research and identified common themes. Consistent with the previous sections, we organize knowledge gaps and future research directions according to the six themes previously identified.

\subsection{Mitigating community flood losses}

Although studies included in this review indicate that acquiring open space and conserving wetlands are effective flood risk management strategies, the majority of these studies are limited in terms of their scope and generalizability. Indeed, most of the studies included under this theme assessed the effectiveness of these strategies in communities along the Gulf Coast or within one watershed (e.g., Brody et al. 2007a, 2008, 2011, 2014). More work needs to be done to look at the effectiveness of these strategies in multiple settings, including inland states. This is especially true given that recent reports indicate that flood disasters are becoming more prevalent in inland states as opposed to coastal states (Pew Charitable Trusts 2018).

\subsection{FEMA's Community Rating System program}

Studies assessing the CRS have generally relied on secondary data and have employed both cross-sectional and longitudinal designs to determine the factors influencing initial and continued participation (e.g., Sadiq and Noonan 2015a, b). Although these designs have significantly contributed to our understanding on why some communities participate in the CRS when others do not, they are limited in that they do not provide insights on the decision-making processes surrounding participation. Hence, scholars should consider 
gathering primary data and employing qualitative methodologies to further establish the factors influencing participation (Sadiq and Noonan 2015a). Determining the drivers motivating communities to adopt certain CRS activities represents an additional area of research that deserves more empirical attention. For example, future studies should explore how political activism, changes in flood risk maps, social capital, and learning influence the level at which communities participate in the CRS (Sadiq and Noonan 2015b).

\subsection{Perceptions and responses to flood events and policies}

Several knowledge gaps exist in regard to understanding perceptions and responses to flood events and policies. For example, there is a need for more research that establishes what stakeholders should be involved during both the planning and recovery stages (Albright and Crow 2015b). Similarly, there is a need to further establish what factors are driving participation in flood planning and recovery processes (Albright and Crow 2015b). There is also a need for more research that examines how individuals perceive flood risks, where they obtain information on their flood risks, and what type of information they are consuming (Kousky and Kunreuther 2010). Such knowledge would improve our understanding on what communication and information modes are most effective. Finally, additional research is needed to better understand how local governments respond to flood policies (Berke et al. 2014; Paul and Milman 2017).

\subsection{Understanding communities' vulnerabilities and flood risks}

Similar to the previous sections, small sample sizes and limited geographic focus are the main limitations associated with studies included under this theme. Hence, multistate and national-level studies would prove beneficial in further understanding why certain communities are more vulnerable to flood disasters and have greater flood risks. An additional limitation associated with this theme is that studies assessing the relationship between socially vulnerable populations and flood casualties have not yet developed empirical conclusions about why these individuals are significantly more likely to be harmed by floods (Zahran et al. 2008). Qualitative studies would help remedy this knowledge gap as such studies could provide a better understanding of how socially vulnerable groups experience flood events and the challenges associated with preparedness and recovery (Chakraborty et al. 2014; Zahran et al. 2008). Finally, more research on the factors influencing local communities to reduce their vulnerabilities through mitigation is needed (Brody et al. 2009b, 2010). For example, researchers should further examine the relationship between local flood mitigation strategies and floodplain percentages, organizational capacity, prior flood experience, and socioeconomic characteristics (Brody et al. 2010).

\subsection{Flood mitigation tools}

Studies assessing the tools available to floodplain managers for delineating flood risks suggest that multiple flood mapping models and tools should be employed. However, more work is needed to determine which models and tools are most effective at capturing flood risks. Specifically, future studies should compare and contrast different modeling platforms across various geographic settings to determine their efficacy at capturing flood risk (Blessing et al. 2017; Brody et al. 2012a). Furthermore, future studies should examine the effect of different land cover types (e.g., wetlands or forests) on various models' ability to capture flood risk 
(Blessing et al. 2017). Finally, future work should employ spatial models to determine the factors contributing to "hotspots" of flood damage (Brody et al. 2012a, p. 96).

\subsection{Communities' efforts to plan for flood events}

Given that only two of the 60 studies included in this review explicitly looked at how communities plan for floods, much more research is needed. For example, a national-level study that examines the relationship between plan quality, implementation, and flood losses would provide practitioners with a better understanding of how to design and implement plans to ensure their efficacy (Kang 2009). Furthermore, additional attention needs to specifically be given toward plan implementation. For example, scholars should seek to determine the factors that influence the degree of plan implementation (Kang 2009). Additional focus should also be given toward understanding why some communities do not remain compliant with mandates for mitigation plans and identifying remedies to encourage compliance (Bailey 2017).

\section{Conclusion}

The primary purpose of this study was to conduct a systematic review of the diverse body of research on community flood risk management in the USA. In doing so, the authors synthesized the major findings from the included studies to develop practical lessons for flood management decision-makers. In fact, this study identified seven practical lessons that, if implemented, could not only help flood management decision-makers better understand communities' flood risks, but could also reduce the impacts of flood disasters and improve communities' resilience to future flood disasters.

This study has a few limitations that are worth mentioning. First, despite our three-stage search procedure, it is possible that we missed some relevant studies on community flood risk management. Second, our review focuses on community flood risk management studies conducted in the USA. There is a body of research in this area outside of the USA. For example, several community-level flood mitigation studies have been conducted in the Netherlands. Such internationally based studies may offer additional practical recommendations for improving community resilience to flood risks within the USA. Third, a few of the practical lessons are based on relatively few studies. Hence, some of the nuances associated with these lessons might not be accounted for. Despite these limitations, this study offers an important contribution to the community flood risk management scholarship and practice by providing critical insights on the current state of research as well as offering feasible and practical lessons for improving flood risk management and enhancing communities' resilience to future flood disasters.

Acknowledgements This article is based on research funded by the US National Science Foundation (NSF) Grant No. 1635381. The findings and opinions are those of the authors and do not necessarily represent the NSF. The authors are grateful to Drs. Sam Brody, Jeffrey Czajkowski, Meri Davlasheridze, Wesley Highfield, Craig Landry, and Sammy Zahran for reviewing our list of studies to be included in this review.

\section{Appendix}

See Table 1. 
Table 1 Major findings from empirical studies on community flood risk management organized by research themes $(N=60)$

Citation $\quad$ Major findings

Theme 1: Mitigating communities' flood losses

Brody et al. (2014)

Brody et al. (2008)

Brody et al. (2011)

Brody and Highfield (2013)

Brody et al. (2015b)

Brody et al. (2017)

Brody et al. (2007c)

Brody et al. (2013)

Brody et al. (2012b)

Brody et al. (2015a)

Brody et al. (2007b)
Local configuration of land use plays an important role in predicting the amount of property damage caused by floods. High-intensity development, for example, has the greatest impact on reducing flood risks. In contrast, low-intensity development patterns significantly increase flood losses

Sprawling development, primarily from residential projects, is escalating in coastal Florida and Texas. Moreover, wetland permits issued in Texas are typically located outside of urban areas (78\%) and outside 100-year floodplains (61\%). Conversely, more than half of wetland permits issued in Florida are within urban areas (57\%) and outside of 100year floodplains $(51 \%)$

Clustered, high-intensity development patterns significantly reduce amounts of reported flood property damage. Moreover, increasing percentages of sprawling, low-intensity development leads to increases in flood losses

In the USA, open space protection is an important land use planning tool for reducing flood losses. Indeed, acquiring and protecting open spaces significantly reduces the amount of property damage caused by flood events

The percent increase in palustrine wetlands is, on average, the equivalent to a $\$ 13,975$ reduction in insured flood losses per year, per watershed

Large, expansive and continuous patches of naturally occurring open spaces are effective at reducing the adverse impacts of flood events

Federal permits issued to alter a naturally occurring wetland exacerbate flooding events in coastal watersheds, even after controlling for a variety of environmental and socioeconomic characteristics

More connected and concentrated development patterns result in reduced flood losses

Features of the natural environment help mitigate the adverse impacts of flood events. Moreover, the percentage of the area outside of the 100-year floodplain has the strongest effect of reducing flood losses. Naturally occurring wetlands are another factor associated with reducing flood losses. Furthermore, well-drained soils are critical to reducing stormwater runoff and related flood damages

The location within a coastal watershed and proximity to zones of exposure are important predictors of flood damage to residential properties

Naturally occurring wetlands play an important role in mitigating flood damage. In fact, the alteration of naturally occurring wetlands is the most important built-environment predictor of flood damage 
Table 1 (continued)

Citation Major findings

Brody et al. (2007a)

Burby and French (1981)

Calil et al. (2015)

Esnard et al. (2001)

Grigg et al. (1999)

Highfield and Brody (2006)

Highfield et al. (2014)

Holway and Burby (1993)

Kousky and Walls (2014)

Theme 2: FEMA's Community Rating System program

Asche (2013)
The alteration of naturally occurring wetlands significantly increases the amount of property damage caused by floods. Moreover, non-structural methods such as the CRS program may indirectly encourage development in hazardous areas

A land use management paradox exists whereby factors, which stimulate the adoption of floodplain land use management programs, also lead to development in hazardous area. However, when the extent of existing floodplain development and availability of hazard-free sites are considered when selecting land use management measures, effective programs can be developed

Flood losses can be mitigated through actions that meet both flood risk reduction and conservation objectives. In addition, government-funded buyouts followed by the restoration of targeted lands can support social, environmental, and economic objectives

Seventy-two percent of Nags Head was constructed with close to one-third of the structures within the oceanfront hazard zone. Moreover, a relatively high percentage of structures built prior to Nags Head's participation in the Flood Insurance Rate Mapping program also lie within incipient inlets and VE flood zones

Experience with the 1997 Fort Collins flood affirms the value of mitigation, a functional storm drainage program, and preparation for emergency response

Wetland alteration projects within designated Special Flood Hazard Areas (SFHAs) experience significantly more flood damage than similar projects outside of the SFHA

The adoption of community-level mitigation activities leads to reduced property damages within the Clear Creek Watershed

Elevating buildings to NFIP standards reduces flood losses. Furthermore, adding additional elevation requirements will have little effect on the rate of increase in floodplain development; these requirements must be supplemented with regulation of floodplain land use

Increased property values for homes near protected lands are more than three times larger than the avoided flood damages, thus stressing the continued importance of more traditional conservation values

Population, income, amount of owner-occupied housing, and historical flood risk are predictors of participation in the CRS program 
Table 1 (continued)

Citation Major findings

Brody et al. (2009a)

Fan and Davlasheridze (2014)

Fan and Davlasheridze (2015)

Highfield and Brody (2013)

Highfield and Brody (2017)

Landry and $\mathrm{Li}(2011)$

$\operatorname{Li}(2012)$

Li and Landry (2018)
Local jurisdictions learn from histories of flood risk, and this learning process is expedited under certain conditions. For example, Florida localities are pursuing a form of least-cost learning where they disproportionately select or engage in CRS activities that are less expensive and more politically viable

Among the CRS program activities, people place the highest value on activities concerning repetitive flood loss reduction. Moreover, people significantly value public information disclosure about flood risks and structural mitigation projects (e.g., flood and debris control dams)

Age, ethnicity, race, educational attainment, and prior exposure to risk explain flood risk perceptions.

Additionally, results show significant values for CRS-creditable mitigation activities, which provides empirical evidence for the benefits associated with the program

Three CRS activities, freeboard requirements, open space protection, and flood protection, significantly reduce flood damage

CRS participating communities experience fewer insured flood losses relative to non-CRS participating communities. In fact, CRS participating communities experience, on average, a $41.6 \%$ reduction in flood claims compared to communities with similar characteristics that do not participate in the program

Flood history and physical risk factors increase the likelihood of local hazard mitigation adoption. CRS participation is lower in counties with a greater proportion of senior citizens and greater level of education. In addition, flood hazard mitigation activities at the county level are more likely when a greater number of nested municipalities participate in the CRS

Flood history and physical risk factors increase the likelihood of local hazard mitigation adoption. CRS participation is lower in counties with a greater proportion of senior citizens and a greater level of education. Moreover, flood hazard mitigation activities at the county level are more likely when a greater number of nested municipalities participate in CRS. In addition, participation in the CRS reduces flood property damages

Communities with larger tax revenues, lower levels of crime and unemployment, and more flood experience have a higher number of CRS points. In addition, CRS points are greater in communities with greater median household income and higher population density. Finally, communities tend to invest in activities that are more accessible and offer greater point accumulation 
Table 1 (continued)

\begin{tabular}{ll}
\hline Citation & Major findings \\
\hline Noonan and Sadiq (2017) & The CRS encourages income inequality, but dis- \\
& courages income inequality in floodplains. More \\
& specifically, median incomes are lower in CRS \\
& communities, but rise in floodplains. Additionally, \\
& the CRS attracts poor residents, but relocates them \\
& away from floodplains. Finally, the CRS attracts top \\
& earners, including those located in floodplains
\end{tabular}

Paille et al. (2016)

Higher CRS scores are associated most closely with higher median housing values. Moreover, higher scores are found in parishes with more local municipalities that participate in the CRS program. Finally, the number of floods in the last 5 years and the revenue base of the county do not appear to influence CRS scores

Posey (2009)

The socioeconomic characteristics of a municipality's population are associated with the capacity of municipal leaders to enact collective action to respond to environmental challenges

Sadiq and Noonan (2015a)

Communities that respond to the nonlinear, tiered incentives in the CRS program are different from participating communities that do not. For example, participating communities that enact less flood mitigation have lower flood risks, property values, government payrolls, and population densities. Furthermore, at lower levels of flood mitigation, responsive communities - the ones upgrading to higher levels of subsidy - tend to adopt substantially more passive CRS activities

Sadiq and Noonan (2015b)

Local capacity, flood risk factors, socioeconomic characteristics, and political economy factors are significant predictors of CRS participation

Zahran et al. (2010)

Communities are motivated by the nonlinear incentive design of the CRS and behave strategically. More specifically, communities are motivated by the easy gains embedded in the CRS program

Zahran et al. (2009)

Household flood insurance purchase is strongly correlated with local government mitigation activities (e.g., participation in the CRS), even after adjusting for hazard experience, hazard proximity, and community demography

Theme 3: Perceptions and responses to flood events and flood policies

Albright and Crow (2015a)

Perceptions of problem severity are linked to past flood experiences, type of expertise, and job position. Additionally, who participates in flood recovery processes may influence how flood risks are perceived at the community level

Albright and Crow (2015b)

Communities that have suffered damage across many sectors and have limited financial capacity are more likely to have residents and organizations that are interested and motivated to participate in flood recovery and planning processes

Berke et al. (2014)

Federal policies do not make a difference in local land use actions, but state policy exerts a strong influence 
Table 1 (continued)

\begin{tabular}{ll}
\hline Citation & Major findings \\
\hline Deegan (2007) & $\begin{array}{l}\text { The simulation model developed explains how the } \\
\text { policy environment interacts endogenously with } \\
\text { a natural hazard experience to produce observed } \\
\text { mitigation outcomes }\end{array}$
\end{tabular}

Kick et al. (2011)

Financial variables, perceptions of future risk, attachments to home and community, and the relationship between repetitive flood loss victims and the local flood management officials who help them influence flood victims' mitigation decisions

Kousky and Kunreuther (2010)

Flood risks are increasing and, thus, better flood maps are needed. Property owners in the USA tend to underestimate their flood risks and not purchase flood insurance. Furthermore, the USA has a love affair with levees and prioritizes rebuilding after a flood disaster

Lufoff and Wilkinson (1979)

Patterns and capabilities developed in the community through community actions and through past flood experiences are the best predictors of participation in the federal flood insurance program

Moore and Cantrell (1976)

Recent experience with flooding and community differentiation are the most important variables in determining communities' response to floods. Other factors such as population change, condition of housing, and family income which have been used in other comparative studies of community decision making are not important predictors of response

Paul and Milman (2017)

Openness and the degree of interest of the town in implementing actions prescribed by the top-down adaptation policy (receptivity) mobilize local action

Theme 4: Understanding communities' vulnerabilities and flood risks

Brody et al. (2009b)

Differences exist in the type and degree of flood mitigation implemented in Texas and Florida. For example, Florida has implemented, on average, more diverse and extensive flood mitigation policies than Texas. Moreover, the results suggest that the significant relationship between organizational capacity and local flood mitigation has allowed Florida to implement better flood risk management programs

Brody et al. (2010)

After controlling for contextual characteristics, organizational capacity is a significant factor contributing to the adoption of both structural and non-structural flood mitigation techniques

Chakraborty et al. (2014)

Flood risk differs across flood zones and among sociodemographic groups. Specifically, non-Hispanic Black and Hispanic residents are significantly overrepresented in inland flood zones and underrepresented in coastal flood zones with higher median income and housing values 
Table 1 (continued)

Citation Major findings

Consoer and Milman (2017)

Physical and institutional characteristics drive rural municipalities to prioritize structural over nonstructural flood mitigation measures. Moreover, the adoption of structural and non-structural mitigation measures is influenced by state and federal regulations as well as barriers to accessing state and federal assistance programs

Mogollón et al. (2016)

Landscape features affect the magnitude and duration of floods with return periods less than or equal to 10 years. Hence, larger floods cannot be managed effectively by manipulating landscape structure

Pielke and Downton (2000)

The rise in flood damage in recent decades is related to both climate factors and societal factors. More specifically, increased damage is associated with increased precipitation and with increasing population and wealth

Zahran et al. (2008)

The odds of a flood casualty increase with the presence of socially vulnerable populations as well as the level of precipitation on the day of a flood event, flood duration, property damage caused by the flood, and population density. In addition, the odds of a flood casualty decrease with the number of dams, the level of precipitation on the day before a recorded flood event, and the extent to which localities have adopted and implemented flood mitigation measures

Theme 5: Flood mitigation tools

Blessing et al. (2017)

Spatially distributed hydrological models like Vflo are alternative models for measuring community flood risks

Brody et al. (2012a)

The 100-year floodplain may not be a sufficient marker for delineating flood risk and predicting property damage caused by flood events

Gall et al. (2007)

Hazard United States-Multi-Hazard and Stream Flow Model 3.3 is appropriate workarounds whenever digital flood data are missing

Lathrop et al. (2014)

The user-centered design approach that was adopted is time sensitive, but appears to result in an endproduct that is largely successful in meeting target audiences' needs

Olsen (2014)

The stakeholder-built and national Geographic Information System software decision support system performs well in communicating knowledge of flood risk and risk-reduction options, resulting in significant learning outcomes. In fact, meetings using the stakeholder-built DSS in high-quality meeting facilities perform best. Additionally, the stakeholder-built model is less expensive and more user-friendly for stakeholders 
Table 1 (continued)

\begin{tabular}{ll}
\hline Citation & Major findings \\
\hline Patterson and Doyle (2009) & $\begin{array}{c}\text { Temporally, the Piedmont and Mountain Regions } \\
\text { have limited success at reducing exposure within } \\
\text { the 100-year floodplain, while the Coastal Plain }\end{array}$ \\
successfully reduces exposure. Spatially, there is a \\
significant increase in flood exposure immediately \\
outside the 100-year floodplain in North Carolina
\end{tabular}

Theme 6: Communities' efforts to plan for flood events

Bailey (2017)

The cost of flooding continues to increase despite the creation of all-hazard mitigation plans mandated through the Disaster Mitigation Act of 2000. Flood costs have increased because of mitigation plan mandates; counties with mitigation plans report more flood costs than counties without mitigation plans

Kang (2009)

After controlling for biophysical, built environment, and socioeconomic variables, plan quality has little effect on reducing insured flood losses. Rather, insured flood loss is considerably affected by wetland alteration and a community's location on the coast

\section{References}

Albright EA, Crow DA (2015a) Learning in the aftermath of extreme floods: community damage and stakeholder perceptions of future risk. Risk Hazards Crisis Public Policy 6(3):308-328

Albright EA, Crow DA (2015b) Learning processes, public and stakeholder engagement: analyzing responses to Colorado's extreme flood events of 2013. Urban Clim 14(1):79-93

Asche EA (2013) The effect of flood risk on housing choices and community hazard mitigation. Dissertation, University of California Santa Barbara

Association of State Floodplain Managers (2010) Model job description for a community floodplain manager. https://www.floods.org/ace-files/documentlibrary/CFM/FPM_Model_Job_Description_2010.pdf. Accessed 1 Oct 2018

Bailey LK (2017) Exploring the barriers to effective federal flood mitigation in the Mississippi River region. Dissertation, University of Louisville

Berke PR, Lyles W, Smith G (2014) Impacts of federal and state hazard mitigation policies on local land use policy. J Plan Educ Res 34(1):60-76

Blessing R, Sebastian A, Brody SD (2017) Flood risk delineation in the United States: how much loss are we capturing? Nat Hazards Rev 18(3):1-10

Bouwer LM (2011) Have disaster losses increased due to anthropogenic climate change? Bull Am Meteorol Soc 92(1):39-46

Brody SD, Highfield WE (2013) Open space protection and flood mitigation: a national study. Land Use Policy 32:89-95

Brody SD, Highfield WE, Ryu HC, Spanel-Weber L (2007a) Examining the relationship between wetland alteration and watershed flooding in Texas and Florida. Nat Hazards 40(2):413-428

Brody SD, Zahran S, Highfield WE, Grover H, Vedlitz A (2007b) Identifying the impact of the built environment on flood damage in Texas. Disasters 32(1):1-18

Brody SD, Zahran S, Maghelal P, Grover H, Highfield WE (2007c) The rising costs of floods: examining the impact of planning and development decisions on property damage in Florida. J Am Plann As 73(3):330-345

Brody SD, Davis SE III, Highfield WE, Bernhardt SP (2008) A spatial-temporal analysis of section 404 wetland permitting in Texas and Florida: thirteen years of impact along the coast. Wetlands 28(1):107-116

Brody SD, Bernhardt SP, Zahran S, Kang JE (2009a) Evaluating local flood mitigation strategies in Texas and Florida. Built Environ 35(4):492-515 
Brody SD, Zahran S, Highfield WE, Bernhardt SP, Vedlitz A (2009b) Policy learning for flood mitigation: a longitudinal assessment of the community rating system in Florida. Risk Anal 29(6):912-929

Brody SD, Kang JE, Bernhardt S (2010) Identifying factors influencing flood mitigation at the local level in Texas and Florida: the role of organizational capacity. Nat Hazards 52(1):167-184

Brody SD, Gunn J, Peacock W, Highfield WE (2011) Examining the influence of development patterns on flood damages along the Gulf of Mexico. J Plan Educ Res 31(4):438-448

Brody SD, Blessing R, Sebastian A, Bedient P (2012a) Delineating the reality of flood risk and loss in Southeast Texas. Nat Hazards Rev 14(2):89-97

Brody SD, Peacock WG, Gunn J (2012b) Ecological indicators of flood risk along the Gulf of Mexico. Ecol Indic 18:493-500

Brody SD, Kim H, Gunn J (2013) Examining the impacts of development patterns on flooding on the Gulf of Mexico coast. Urban Stud 50(4):789-806

Brody SD, Blessing R, Sebastian A, Bedient P (2014) Examining the impact of land use/land cover characteristics on flood losses. J Environ Plan Manag 57(8):1252-1265

Brody SD, Highfield WE, Blessing R (2015a) An analysis of the effects of land use and land cover on flood losses along the Gulf of Mexico coast from 1999 to 2009. J Am Water Resour As 51(6):1556-1567

Brody SD, Sebastian A, Blessing R, Bedient PB (2015b) Case study results from southeast Houston, Texas: identifying the impacts of residential location on flood risk and loss. J Flood Risk Manag 51(11):5110-5120

Brody SD, Highfield WE, Blessing R, Makino T, Shepard CC (2017) Evaluating the effects of open space configurations in reducing flood damage along the Gulf of Mexico coast. Landsc Urban Plan $167: 225-231$

Bubeck P, Botzen WJ, Aerts JC (2012) A review of risk perceptions and other factors that influence flood mitigation behavior. Risk Anal 32(9):1481-1495

Burby RJ (2006) Hurricane Katrina and the paradoxes of government disaster policy: bringing about wise governmental decisions for hazardous areas. Ann Am Acad Pol Soc Sci 604:171-191

Burby RJ, French SP (1981) Coping with floods: the land use management paradox. J Am Plan As 47(3):289-300

Calil J, Beck MW, Gleason M, Merrifield M, Klausmeyer K, Newkirk S (2015) Aligning natural resource conservation and flood hazard mitigation in California. PLoS ONE 10(7):1-14

Chakraborty J, Collins TW, Montgomery MC, Grineski SE (2014) Social and spatial inequities in exposure to flood risk in Miami, Florida. Nat Hazards Rev 15(3):1-10

Cigler BA (2017) US floods: the necessity of mitigation. State Local Gov Rev 49(2):127-139

Consoer M, Milman A (2017) Opportunities, constraints, and choices for flood mitigation in rural areas: perspectives of municipalities in Massachusetts. J Flood Risk Manag. https://doi.org/10.1111/jfr3.12302

Cutter SL, Barnes L, Berry M, Burton C, Evans E, Tate E, Webb J (2008) A place-based model for understanding community resilience to natural disasters. Glob Environ Change 18(4):598-606

Deegan MA (2007) Exploring US flood mitigation policies: a feedback view of system behavior. Dissertation, State University of New York at Albany

Eisenman DP, Cordasco KM, Asch S, Golden JF, Glik D (2007) Disaster planning and risk communication with vulnerable communities: lessons from Hurricane Katrina. Am J Public Health 97(1):109-115

Esnard AM, Brower D, Bortz B (2001) Coastal Hazards and the built environment on Barrier Islands: a retrospective view of Nags Head in the late 1990s. Coast Manag 29(1):53-72

Fan Q, Davlasheridze M (2014) Evaluating the effectiveness of flood mitigation policies in the US. Conference paper, Agricultural and applied economics association annual conference

Fan Q, Davlasheridze M (2015) Flood risk, flood mitigation, and location choice: evaluating the national flood insurance program's community rating system. Risk Anal 36(6):1125-1147

Federal Emergency Management Agency (2014a) For communities plagued by repeated flooding, property acquisition may be the answer. https://www.fema.gov/news-release/2014/05/28/communitie s-plagued-repeated-flooding-property-acquisition-may-be-answer. Accessed on 31 Jan 2019

Federal Emergency Management Agency (2014b) Homeowner flood insurance affordability act of 2014. https://www.fema.gov/media-library/assets/documents/95946. Accessed on 31 Jan 2019

Federal Emergency Management Agency (2015) FEMA hazard mitigation assistance brochures. https:// www.fema.gov/media-library/assets/documents/107704. Accessed on 7 April 2018

Federal Emergency Management Agency (2017) Flood zones. https://www.fema.gov/flood-zones. Accessed on 7 April 2018

Gall M, Boruff BJ, Cutter SL (2007) Assessing flood hazard zones in the absence of digital floodplain maps: comparison of alternative approaches. Nat Hazards Rev 8(1):1-12

Gallagher J (2014) Learning about an infrequent event: evidence from flood insurance take-up in the United States. Am Econ J Appl Econ 6(3):206-233 
Galloway GE (2008) Flood risk management in the United States and the impact of Hurricane Katrina. Int J River Basin Manag 6(4):301-306

Grigg NS, Doesken NJ, Frick DM, Grimm M, Hilmes M, McKee TB, Oltjenbruns KA (1999) Fort Collins flood 1997: comprehensive view of an extreme event. J Water Res Plan Man 125(5):255-262

Haddow G, Bullock J, Coppola DP (2011) Introduction to emergency management. Butterworth-Heinemann, Cambridge, MA

Highfield WE, Brody SD (2006) Price of permits: measuring the economic impacts of wetland development on flood damages in Florida. Nat Hazards Rev 7(3):123-130

Highfield WE, Brody SD (2013) Evaluating the effectiveness of local mitigation activities in reducing flood losses. Nat Hazards Rev 14(4):229-236

Highfield WE, Brody SD (2017) Determining the effects of the FEMA community rating system program on flood losses in the United States. Int J Disaster Risk Reduct 21:396-404

Highfield WE, Brody SD, Blessing R (2014) Measuring the impact of mitigation activities on flood loss reduction at the parcel level: the case of the clear creek watershed on the upper Texas coast. Nat Hazards 74(2):687-704

Holway JM, Burby RJ (1993) Reducing flood losses local planning and land use controls. J Am Plan As 59(2):205-216

Horn D, Brown JT (2018) Introduction to FEMA's national flood insurance program (NFIP). Congressional Research Service. https://fas.org/sgp/crs/homesec/R44593.pdf Accessed 1 Oct 2018

Horritt MS, Bates PD (2001) Effects of spatial resolution on a raster based model of flood flow. J Hydrol 253(1-4):239-249

Intergovernmental Panel on Climate Change (2013) Climate change 2013: the physical science basis. Cambridge University Press, Cambridge

Jongman B, Winsemius HC, Fraser SA, Muise SM (2018) Assessment and adaptation to climate changerelated flood risks. Oxford Research Encyclopedia of Natural Hazard Science. http://oxfordre. com/naturalhazardscience/view/10.1093/acrefore/9780199389407.001.0001/acrefore-9780199389 407-e-278?print=pdf Accessed 17 Jan 2019

Kang JE (2009) Mitigating flood loss through local comprehensive planning in Florida. Dissertation, Texas A\&M University

Kellens W, Terpstra T, De Maeyer P (2013) Perception and communication of flood risks: a systematic review of empirical research. Risk Anal 33(1):24-49

Kick EL, Fraser JC, Fulkerson GM, McKinney LA, De Vries DH (2011) Repetitive flood victims and acceptance of FEMA mitigation offers: an analysis with community-system policy implications. Disasters 35(3):510-539

Kousky C, Kunreuther H (2010) Improving flood insurance and flood-risk management: insights from St. Louis, Missouri. Nat Hazards Rev 11(4):162-172

Kousky C, Walls M (2014) Floodplain conservation as a flood mitigation strategy: examining costs and benefits. Ecol Econ 104:119-128

Landry CE, Li J (2011) Participation in the community rating system of NFIP: empirical analysis of North Carolina counties. Nat Hazards Rev 13(3):205-220

Lathrop R, Auermuller L, Trimble J, Bognar J (2014) The application of WebGIS tools for visualizing coastal flooding vulnerability and planning for resiliency: the New Jersey experience. Int J Geo-Inf 3(2):408-429

Li J (2012) Community flood hazard mitigation and the community rating system of national flood insurance program. Dissertation, East Carolina State University

Li J, Landry CE (2018) Flood risk, local hazard mitigation, and the community rating system of the national flood insurance program. Land Econ 94(2):175-198

Lufoff AE, Wilkinson KP (1979) Participation in the national flood insurance program: a study of community activeness. Rural Sociol 44(1):137

Mees H, Tempels B, Crabbé A, Boelens L (2016) Shifting public-private responsibilities in Flemish flood risk management. Towards a co-evolutionary approach. Land Use Policy 57:23-33

Mittler E, Morgan L, Shapiro M, Grill KY (2006) State roles and responsibilities in the national flood insurance program. American Institutes for Research. https://biotech.law.lsu.edu/disasters/insurance/nfip_ eval_state_roles.pdf. Accessed 1 Oct 2018

Mogollón B, Frimpong EA, Hoegh AB, Angermeier PL (2016) An empirical assessment of which inland floods can be managed. J Environ Manag 167(1):38-48

Moore DE, Cantrell RL (1976) Community response to external demands: an analysis of participation in the federal flood insurance program. Rural Sociol 41(4):484

Morrison A, Westbrook CJ, Noble BF (2017) A review of the flood risk management governance and resilience literature. J Flood Risk Manag. https://doi.org/10.1111/jfr3.12315 
National Weather Service (2017) Billion-dollar weather and climate disasters. https://www.ncdc.noaa.gov/ billions/events/US/1980-2017. Accessed on 15 Jan 2018

Noonan DA, Sadiq AA (2017) Flood risk management: exploring the impacts of the community rating system program on poverty and income inequality. Risk Anal 38(3):489-503

Olsen VBK (2014) Proposing a realistic interactive visualization model and testing its effectiveness in communicating flood risk. Dissertation, University of Maryland

Paille M, Reams M, Argote J, Lam NSN, Kirby R (2016) Influences on adaptive planning to reduce flood risks among parishes in South Louisiana. Water 8(2):1-14

Patterson LA, Doyle MW (2009) Assessing effectiveness of national flood policy through spatiotemporal monitoring of socioeconomic exposure. J Am Water Resour As 45(1):237-252

Paul M, Milman AA (2017) A question of 'fit': local perspectives on top-down flood mitigation policies in Vermont. J Environ Plan Manag 60(12):2217-2233

Pew Charitable Trusts (2018). Where it rains, it floods: nationwide disasters underscore the need for flood policy overhaul. https://www.pewtrusts.org/en/research-and-analysis/articles/2018/01/25/where-itrains-it-floods. Accessed 1 Oct 2018

Pielke RA Jr, Downton MW (2000) Precipitation and damaging floods: trends in the United States, 193297. J Climate 13(20):3625-3637

Posey J (2009) The determinants of vulnerability and adaptive capacity at the municipal level: evidence from floodplain management programs in the United States. Global Environ Change 19(4):482-493

Sadiq AA (2017) Determinants of organizational preparedness for floods: US employees' perceptions. Risk Hazards Crisis Public Policy 8(1):28-47

Sadiq AA, Noonan DS (2015a) Local capacity and resilience to flooding: community responsiveness to the community ratings system program incentives. Nat Hazards 78(2):1413-1428

Sadiq AA, Noonan DS (2015b) Flood disaster management policy: an analysis of the United States community ratings system. J Nat Resour Policy Res 7(1):5-22

Sadiq AA, Tyler J, Noonan DS, Norton RK, Cunniff SE, Czajkowski J (2018) A review of the Federal Emergency Management Agency's Community Rating System program. Risk Management and Decision Processes Center. https://riskcenter.wharton.upenn.edu/wp-content/uploads/2018/07/WP201804_CRSLiterature-Review_Sadiq-etal.pdf. Accessed 30 Mar 2019

Strother L (2016) The national flood insurance program: a case study in policy failure, reform, and retrenchment. Policy Stud J. https://doi.org/10.1111/psj.12189

Thompson RR, Garfin DR, Silver RC (2017) Evacuation from natural disasters: a systematic review of the literature. Risk Anal 37(4):812-839

Tyler J (2018) The relationship between the community rating system program and business disaster recovery. Natural Hazards Center. https://hazards.colorado.edu/quick-response-report/the-relationship-betwe en-the-community-rating-system-program-and-business-disaster-recovery. Accessed 1 Oct 2018

Tyler J, Sadiq AA (2018) Business disaster continuity and recovery in the aftermath of Hurricane Irma: exploring whether community-level mitigation activities make a difference. Nat Hazards Rev 20(1):1-12

Zahran S, Brody SD, Peacock WG, Vedlitz A, Grover H (2008) Social vulnerability and the natural and built environment: a model of flood casualties in Texas. Disasters 32(4):537-560

Zahran S, Weiler S, Brody SD, Lindell MK, Highfield WE (2009) Modeling national flood insurance policy holding at the county scale in Florida, 1999-2005. Ecol Econ 68(10):2627-2636

Zahran S, Brody SD, Highfield WE, Vedlitz A (2010) Non-linear incentives, plan design, and flood mitigation: the case of the Federal Emergency Management Agency's community rating system. J Environ Plan Manag 53(2):219-239

Publisher's Note Springer Nature remains neutral with regard to jurisdictional claims in published maps and institutional affiliations. 